\title{
A PRODUÇÃO CIENTÍFICA SOBRE IMIGRAÇÃO E EDUCAÇÃO NO BRASIL: análise historiográfica das instituições escolares étnicas
}

\author{
Vera Lucia Martiniak \\ Universidade Estadual de Ponta Grossa- UEPG
}

\section{RESUMO}

Este texto apresenta uma análise da produção científica que aborda as temáticas relacionadas à história das instituições escolares destinadas à educação de imigrantes. A coleta dos dados deu-se por meio dos sites dos programas de pós-graduação de algumas instituições, bem como a consulta ao banco de dados mantido pela CAPES (Coordenação de Aperfeiçoamento de Pessoal de Nível Superior). Fez-se uma análise dos dados encontrados que posteriormente foram organizados em tabelas e organizados em banco de dados. De acordo com alguns autores a educação de imigrantes ainda é um tema com poucos trabalhos publicados. Dos trabalhos publicados a grande maioria concentra-se na região Sul, devido a sua influência fortemente marcada pela presença de imigrantes europeus. Em relação à História das Instituições Escolares observa-se um aumento no número de trabalhos, em decorrência do crescimento dos programas de pós-graduação no Brasil a partir de 1990. A criação dos Grupos de Trabalho em diversas áreas acabou dando um incremento na qualidade e quantidade de trabalhos.

Palavras-chave: Historiografia; Instituições Escolares; Educação de Imigrantes.

\section{THE SCIENTIFIC PRODUCTION ON IMMIGRATION AND EDUCATION IN BRAZIL: historiographical analysis of ethnic educational institutions}

\begin{abstract}
This text presents an analysis of scientific production that addresses the themes related to the history school institutions destined for immigrant education. Data collection there has been through the websites of the graduate programs of some institutions, as well as consulting the database maintained by CAPES (Higher Education Personnel Training Coordination). There was an analysis of the data found that were later organized in tables. According to some authors to immigrant education is still a subject with few published studies. Papers published the vast majority concentrated in the South, due to its influence strongly marked by the presence of European immigrants. Regarding the History of School Institutions observed an increase in the number of jobs, due to the growth of programs graduate in Brazil since 1990. the creation of the Working Groups in several areas ended up giving an increase in the quality and quantity of work.
\end{abstract}

Key-words: Historiography; School institutions; Immigrant Education

\section{Introdução}

O texto tem por objetivo apresentar, por meio de uma análise interpretativa, a produção do conhecimento acadêmico referente a história das instituições escolares e, especificamente, as instituições escolares criadas para atender grupos de imigrantes europeus, durante o processo migratório ocorrido no século XVIII e início do século XX no Brasil. Neste contexto histórico a educação pública era precária e não atendia suficientemente as crianças brasileiras ocasionando a criação de escolas étnicas mantidas pelos próprios imigrantes. 
Este estudo insere-se em um projeto mais amplo de pesquisa que busca analisar a constituição das escolas étnicas na região dos Campos Gerais, Paraná, a partir da criação da Província do Paraná, em 1853. Assim, optou-se como procedimento inicial pesquisar, nos Programas de Pós-Graduação, as dissertações e teses produzidas que abordaram a institucionalização das escolas étnicas no país, indiferente da etnia. Este trabalho de levantamento e catalogação tem se constituído como ferramenta essencial para as pesquisas nas diversas áreas de conhecimento, como elemento que busca identificar, conhecer e compreender as temáticas produzidas por pesquisadores do país. A elaboração do Estado da Arte ou do Conhecimento permite verificar os avanços, as lacunas, as possibilidades e os limites da pesquisa e especificamente neste caso, corroborar para a sistematização da produção acadêmica referente à área da História da Educação e vislumbrar os caminhos que ainda precisam ser trilhados. Nesta direção, este estudo caracteriza-se como um Estado do Conhecimento, pois, aborda apenas um setor das publicações sobre o tema estudado, diferentemente do Estado da Arte que abrangem toda uma área do conhecimento, como a análise de dissertações, teses, produções em congressos na área, estudos sobre as publicações em periódicos da área (ROMANOWSKI; ENS, 2006).

O levantamento e análise das produções possibilitam que seja ordenado o conjunto de informações e resultados obtidos, que permitem a "[...] indicação das possibilidades de integração de diferentes perspectivas, aparentemente autônomas, a identificação de duplicações ou contradições e a determinação de lacunas ou vieses" (SOARES, 2000).

Neste sentido, os avanços da pesquisa histórica permitem vislumbrar um alargamento dos objetos da história da educação (MAGALHẪES, 1999), que antes não eram contemplados nos estudos da área. Com este alargamento, muitas temáticas emergiram nas pesquisas e tornaram-se recorrentes nas investigações realizadas por grupos de pesquisas e por pesquisadores ligados à pós-graduação. Configuram-se nestas investigações as pesquisas que tratam de temáticas relacionadas ao campo de estudos das instituições educativas com enfoque na institucionalização, nos agentes, nos saberes e nas práticas. Em se tratando das instituições escolares o fio condutor é a análise da sua constituição em determinado espaço e tempo, pois "[...] o processo de criação de instituições coincide com o processo de institucionalização de atividades que antes eram exercidas de forma não institucionalizada, assistemática, informal, espontânea" (SAVIANI, 2007, p. 5).

Constatado este avanço nas pesquisas históricas percebe-se também a presença e a renovação da concepção teórico-metodológica, superando uma historiografia baseada na descrição de fatos, acentuados pela visão positivista. Nesta ótica, as ciências da sociedade, assim como as da natureza, limitam-se à observação e à explicação causal dos fenômenos, de forma objetiva, neutra, livre de julgamentos de valor ou ideologia, descartando previamente todas as pré-noções e preconceitos (LOWY, 1994), pois esta é uma das premissas básicas que estruturam o positivismo clássico.

Em oposição a uma visão positiva a pesquisa pretende tomar a história como fio condutor e considerar, a partir do enfoque teórico do materialismo histórico, o homem inserido em uma sociedade procurando desvelar a partir dos determinantes as múltiplas relações que se estabelecem.

\section{Encaminhamentos e procedimentos para o desenvolvimento da pesquisa}

Para o levantamento e seleção das teses e dissertações produzidas definiram-se cinco categorias que direcionaram a pesquisa: instituições escolares, imigração, imigrantes, 
educação e escolas étnicas. As categorias definidas não foram elencadas aleatoriamente, mas foram selecionadas a partir das linhas de pesquisas do grupo e, resultam dos esforços dos seus integrantes em levantar e organizar as produções científicas da área. O processo de levantamento das produções tem se tornado uma atividade imprescindível para alunos e bolsistas da graduação e da pós-graduação em suas pesquisas. O Estado da Arte e do Conhecimento apresentam a trajetória das pesquisas, de um determinado campo ou área, seus avanços, possibilidades e limites que impulsionam as produções posteriores. Neste sentido, o levantamento da produção existente, tem se constituído em um instrumento de avaliação e análise que permite direcionar as pesquisas e fortalecer a área de conhecimento, pois "[...] podem conduzir à plena compreensão do estado atingido pelo conhecimento a respeito de determinado tema - sua amplitude, tendências teóricas, vertentes metodológicas". (SOARES; MACIEL, 2000, p. 9).

A partir da definição das categorias analíticas procedeu-se a busca por dissertações e teses por meio das informações contidas nos bancos de dados de programas de pósgraduação e também no banco de teses mantido pela Coordenação de Aperfeiçoamento de Pessoal de Nível Superior - CAPES. A análise da produção científica centrou nas teses e dissertações desconsiderando artigos e livros, advindos destas produções. Para delimitação definiu-se ainda, que a busca abrangeria o período histórico de 2006 a 2012, pois se entende que há uma ampliação dos estudos que abordam a temática da educação e imigração.

Com estas definições o processo de levantamento do estado do conhecimento cumpriu as seguintes etapas:

1) levantamento da produção científica na base de dados já definida, que aborda a temática sobre educação e imigração, considerando as produções que apresentavam em seu título, no resumo ou palavras-chave as categorias indicadas. A partir do material encontrado, optou-se em ampliar as categorias definidas inicialmente, pois a leitura do título e das palavras-chave não correspondia com o conteúdo analisado na produção. Buscando ampliar a pesquisa definiu-se que a investigação compreenderia os termos "cultura escolar" e "identidade" que foram recorrentes nos resultados da busca.

2) leitura do material coletado para a identificação da temática e da proposta da pesquisa, sendo necessário o acesso ao conteúdo total das produções selecionadas, pois em alguns casos o resumo não apresentava as informações necessárias para a elaboração da síntese interpretativa. Os textos completos, das teses e dissertações, foram consultados a partir dos acervos disponíveis na base de dados dos programas de pós-graduação.

3) organização de um banco de dados com informações dos trabalhos selecionados, considerando: instituição, nome do autor, título, ano de obtenção, área do conhecimento e nível de titulação acadêmica. A elaboração de um banco de dados para o pesquisador permite visualizar a produção científica encontrada e emitir análises a respeito das categorias elencadas.

4) análise interpretativa dos dados coletados a partir das categorias definidas e produção do texto final.

Este texto apresenta uma discussão sobre a importância do estudo da História da Educação e das Instituições Escolares, bem como a análise da produção historiográfica encontrada sobre a imigração e a educação. A opção por esta temática leva em conta a contribuição que se dará para a história regional a partir da reconstrução histórica das instituições escolares e das especificidades acerca do processo imigratório no Paraná e especificamente, na região dos Campos Gerais, PR. A produção científica no campo da história da educação tem instigado novas investigações, principalmente a expansão dos 
estudos que abordam a história das instituições escolares e que contribuem para o avanço do conhecimento na área (VILELLA, 2005).

\section{O estudo acerca da história das instituições escolares}

A história da educação, enquanto área de conhecimento, possui marcas na sua trajetória relacionadas com a proximidade com a disciplina de Filosofia da Educação. Na sua origem e desenvolvimento, a história da educação esteve presente nos currículos dos cursos de formação de professores. Entretanto, este cenário alterou-se a partir dos anos 1960 e início dos 70, com o surgimento dos Programas de Pós-Graduação em Educação no país; com a criação do Grupo de Trabalho "História da Educação" da Associação Nacional de Pós-Graduação e Pesquisa em Educação - ANPEd e, com a criação do Grupo de Estudos e Pesquisas "História, Sociedade e Educação no Brasil" - HISTEDBR a partir da década de 1980 (VIDAL; FARIA FILHO, 2003). A produção de pesquisas na área foi incrementada e cresceu substantivamente a partir do desenvolvimento e criação dos cursos de pós-graduação e dos grupos de pesquisas, no Brasil. Ao mesmo tempo constituiu-se identidade, ainda que multifacetada e plural, do historiador da educação, bem como adquiriu uma identidade epistemológica, embora seja marcada por ambiguidades e fragilidades quanto à conceitualização e definição de um campo disciplinar (MAGALHÃES, 2004).

A partir da década de 1990 intensificaram-se os estudos sobre instituições escolares, constituindo-se como uma das principais linhas de renovação da historiografia da educação. A instituição educativa é apresentada com suas ações pedagógicas e organizacionais no complexo binômio espaço/tempo, em que se inter-relacionam elementos materiais e humanos, um conjunto de categorias conceituais que podem ser percebidas e analisadas dentro da estrutura escolar, tais como o tempo, o calendário escolar, o currículo, os espaços, os professores, os manuais escolares, a interação educativa (MAGALHÃES, 2204). Assim, a investigação “[...] constrói-se entre a materialidade, a representação e a apropriação. As instituições educativas e por conseqüência a sua história constituem a representação discursiva, memorística e antropológica das mais complexas dialécticas educacionais" (MAGALHÃES, 2004, p. 64).

Em se tratando das instituições escolares de imigrantes, o fio condutor é a análise da sua constituição em determinado espaço e tempo, pois a sua reconstrução histórica está relacionada com o processo de institucionalização da educação que é “[...] correlato do processo de surgimento da sociedade de classes que, por sua vez, tem a ver com o processo de aprofundamento da divisão do trabalho" (SAVIANI, 2007, p. 9). Nesta direção, o emprego da palavra "reconstrução" possui intencionalidade ao garantir que o objeto seja reconstruído no plano do conhecimento, ou seja, das condições efetivas em que se deu a construção das instituições escolares (SAVIANI, 2007).

O estudo acerca da reconstrução história das instituições escolares traduz-se como importante pesquisa, pois

[...] não há instituição escolar ou educativa que não mereça ser objeto de pesquisa histórica. $\mathrm{O}$ maior ou menor grau de relevância de uma instituição seja do ponto de vista econômico, político, educacional e segundo critérios específicos, não pode tolher a escolha do historiador. Não há instituição sem história e não há história sem sentido (SANFELICE, 2007, p. 79). 
Toda instituição escolar possui sua singularidade e, por isso, não pode ser analisada de forma isolada do contexto. Para o empreendimento da análise deve-se ir além das aparências, ou seja, deve-se buscar entender o que a instituição escolar " [...] institui para si, para seus sujeitos e para a sociedade na qual está inserida? Mais radicalmente ainda: qual é o sentido do que foi instituído?" (SANFELICE, 2006, p. 24).

O presente estudo implica na compreensão dos interesses ideológicos que desencadearam a necessidade de institucionalização das escolas de imigrantes, sem desconsiderar o movimento de articulação com o contexto nacional e as relações com os países europeus que passaram pelo movimento imigratório. A escolarização das crianças, filhas de imigrantes, se deu por meio das reivindicações das famílias pela construção e manutenção de escolas públicas, a fim de garantir a aprendizagem da língua nacional. Entretanto, quando não era possível manter escolas públicas os próprios imigrantes se organizavam para oferecer educação para seus filhos.

Diante deste contexto de precariedade e descaso com a instrução pública, os ideais propagados pelos dirigentes defendiam a necessidade de instruir a população como meio de regenerá-la e assim, torná-la apta para participar do progresso do país. Para tanto, a instrução cumpriu um papel fundamental, ou seja, permitiu que o Império se colocasse ao lado das nações civilizadas. A instrução da população possibilitaria romper as trevas que caracterizavam o passado colonial; bem como possibilidade de estabelecer o primado da Razão, superando a 'barbárie dos Sertões' e a 'desordem' das Ruas; além da oportunidade de usufruir os benefícios do progresso (MATTOS, 1990).

A constituição de escolas primárias foi gradual e lenta nas províncias e as poucas que foram criadas, muitas funcionavam em estado precário, com falta de materiais e utensílios, e muitas vezes não haviam professores disponíveis para atuar neste nível e nem local adequado para o prédio escolar. Muitas escolas funcionavam nas casas dos professores, em locais impróprios e inadequados para os alunos. Neste sentido, pode-se inferir que a educação no período imperial foi marcada por um caráter elitista e discriminador, pois o ensino ainda apresentava resquícios da época colonial, ou seja, não havia nenhum compromisso e interesse com a instrução da população. As tentativas para organização do ensino público, tomadas pelos governantes da província, esbarravam na estrutura centralizadora do Império. Como o governo não priorizou o ensino público passou a apoiar as iniciativas particulares para a manutenção da instrução por meio de subvenções.

A vinda de europeus para o Brasil teve como objetivo a ocupação dos espaços vazios propícios ao desenvolvimento da agricultura, do comércio e da indústria e a substituição da força de trabalho escrava pela força de trabalho assalariada. Com isso houve o incentivo ao desenvolvimento das cidades, que estimularam o comércio e fomentaram a criação de serviços de infra-estrutura para atender as necessidades da população.

A historiografia paranaense aponta duas vertentes em relação ao trabalho escravo e a substituição pelo trabalhador assalariado de origem imigrante. Alguns historiadores, como Wilson Martins, insistem, a partir dos dados que eles próprios apresentam, em afirmar que os negros não tiveram expressão numérica ou cultural na formação da população paranaense. Diante dos dados o autor concluir que ao "[...] lado da imigração, é a inexistência da grande escravatura o aspecto mais característico da história social do Paraná, ambos o distinguindo inconfundivelmente de outras regiões brasileiras, como a que compreende o Rio de Janeiro e o Nordeste, por exemplo".(MARTINS, 1989, p. 128).

Na mesma direção de Martins (1989), Romário Martins (1939) e Ruy Wachowicz (1967) elaboraram uma interpretação em que minimizaram o trabalho escravo e relegaram 
a existência e a contribuição desta etnia na formação histórica paranaense. A negação da presença de escravos negros no Paraná confronta-se com a proposta de branqueamento da população e o predomínio de europeus, principalmente a alemã, na província.

Contrariamente a posição adotada por Martins (1989) outros estudos surgiram evidenciando a contribuição da população negra escrava, dentre eles, Otavio Ianni na obra "As Metamorfoses do Escravo", ressaltou que "[...] o Paraná dos séculos XVII, XVIII e XIX era uma sociedade fundada na força de trabalho escrava" (1988, p. 149), sendo substituída posteriormente por um trabalhador que atendesse as necessidades da produção e do projeto de sociedade capitalista.

De qualquer modo, se reconhece que existe a oposição na historiografia regional em relação à presença e a contribuição dos escravos africanos na configuração da sociedade paranaense. Muitas pesquisas e estudos têm se dedicado a analisar a escravidão sob diferentes aspectos e com perspectivas teóricas e metodológicas diversas. Entretanto, poucas têm se dedicado a analisar as relações entre a substituição do trabalho escravo pelo trabalho assalariado, principalmente do trabalhador europeu, na perspectiva do materialismo histórico.

$\mathrm{Na}$ busca realizada entre os anos de 2006 a 2012 foram encontradas 26 produções acadêmicas que abordam temáticas acerca da escravidão e da imigração, sendo predominante os estudos relacionados às instituições escolares e identidade cultural. Recentemente, a pesquisa desenvolvida pela coordenadora do GT HISTEDBR/Campos Gerais, Maria Isabel Moura Nascimento (2012) analisou a proposta de educação dos negros expressa nos documentos dos Congressos Agrícolas, realizados no Rio de Janeiro e Pernambuco. Nesta pesquisa a autora destaca que a ideia de instituição escolar se concretizou após a abolição, apenas buscando "[...] atender aos interesses dos fazendeiros ex-escravocratas principalmente da região sudeste, pela forma diminuta como foram criadas as escolas públicas para a classe mais pobre do país"(NASCIMENTO, 2012, p. 80).

A historiografia regional demonstra a relevância do tema e a importância de analisar a substituição do trabalho escravo pelo trabalho assalariado. Nesse contexto histórico, cabe destacar a necessidade de constituição de escolas étnicas para os filhos dos imigrantes já que as escolas públicas eram precárias, escassas e não atendiam as necessidades da população brasileira.

No fim do século XIX, com a organização de trabalho assalariado, começaram a surgir, em vários locais do país, núcleos de pequenas propriedades agrícolas de base familiar. Para suprir a demanda de mão-de-obra nas grandes fazendas surgiram os núcleos de colonização estrangeira, principalmente no Sul do país. Nesse contexto, as relações de produção centradas no senhor e no escravo foram substituídas pela relação entre o capitalista e o empregado, os quais passaram a constituir a nova estrutura econômica da sociedade que edifica a superestrutura capitalista (SINGER, 1980).

A partir do processo de industrialização do país, verificou-se um crescimento da demanda social por escola, juntamente com a mobilização das elites intelectuais em torno da reforma e da expansão educacional. A necessidade de educação não era percebida como fundamental e foi, portanto, relegada em segundo plano pelo poder político, induzindo profundas modificações no quadro das aspirações educacionais, no discurso e na ação do próprio Estado (XAVIER, 1990). 


\section{O Estado do Conhecimento acerca da produção historiográfica}

O levantamento da produção acadêmica possibilitou a identificação de alguns pontos em comum dentre as pesquisas selecionadas. O primeiro deles é o perceptível aumento da produção sobre o tema, relacionado diretamente com a ampliação dos programas de pós-graduação e a atuação dos grupos de pesquisa em História da Educação. Nesta direção, os grupos de pesquisas têm contribuído significativamente para a socialização das pesquisas, e concomitantemente, impulsionam a investigação de temas que ainda carecem de discussões e aprofundamentos. Dentre estes temas emerge a necessidade de aprofundar os estudos a respeito das instituições educativas sugerido por Saviani (2007) em formular um programa amplo relativo à reconstrução histórica a partir dos grupos de pesquisas e programas de pós-graduação no país.

A proposta é ousada, mas, pode apresentar na sua concretude a produção de um material valiosíssimo para o entendimento acerca da constituição das instituições escolares no país e o direcionamento de pesquisas e estudos voltados para a compreensão do papel que desempenharam na sociedade capitalista.

Especificamente, tratando-se das instituições escolares étnicas o quantitativo das produções acadêmicas que tratam sobre a educação de imigrantes no Brasil, pode ser retratado a partir do seguinte quadro:

Quadro 1 - Distribuição das Teses e Dissertações, por ano.

\begin{tabular}{ccc}
\multirow{2}{*}{ Ano } & \multicolumn{2}{c}{ PRODUÇÃO } \\
2006 & Dissertações & Teses \\
2007 & 1 & 1 \\
2008 & 3 & 2 \\
2009 & 1 & 0 \\
2010 & 0 & 3 \\
2011 & 2 & 0 \\
2012 & 8 & 0 \\
TOTAL & 1 & 4 \\
\hline
\end{tabular}

Fonte: Elaborada pela autora

Entre 2006 e 2012 foram defendidas 26 teses e dissertações, com predomínio de 16 dissertações de mestrado, que constituem $64 \%$ da produção, enquanto as teses representam $36 \%$ do total apresentado no quadro 1.

Os dados apresentados demonstram um acréscimo na produção nos dois últimos anos, que pode ser explicado pelo direcionamento dos estudos oriundos de pesquisadores que participam de grupos de pesquisas e aprofundam sua produção na temática acerca da imigração no Brasil. Dentre os grupos de pesquisas que aprofundam os estudos a respeito 
da imigração no Brasil destaca-se o grupo "História da Educação, Imigração e Memória" coordenado pelo professor Lucio Kreutz, que realizam pesquisas que abordam o processo escolar étnico entre imigrantes no Brasil e estudos comparativos sobre aspectos do processo escolar entre as diversas etnias de imigrantes no Brasil.

Na tentativa de compreender como essa produção está constituída optou-se também pela análise do seu conteúdo a partir do objeto da pesquisa e objetivos que nortearam a investigação, bem como as temáticas que se relacionam com a educação de imigrantes. Dentre estas temáticas, pode-se destacar a recorrência da discussão acerca da influência da religião na formação das comunidades de imigrantes, como fator para identificação cultural. Na pesquisa de Maschio $(2012$, p. 37) destaca-se a presença da Igreja Católica que exerceu forte poder nas colônias de imigrantes italianos, pois " [...] intentou disseminar e manter a fé por meio das congregações religiosas e suas escolas confessionais, imprimindo nos imigrantes e seus descendentes o selo da religião cristã católica". A importância atribuída à manutenção da religião dos imigrantes conflitava com os interesses da coroa portuguesa nos estudos de Negrão (2008). Anteriormente à proclamação da república no país o governo imperial declarou-se "[...] oficialmente um governo católico, sobre forte influência da Coroa Portuguesa. A Igreja Católica tinha o seu direcionamento traçado pelo catolicismo luso-brasileiro ou regime de padroado, tendo como características fundamentais a subserviência ao Imperador e ao estado" (NEGRÃO, 2008, p. 51).

De acordo com seus estudos a divergência religiosa também foi um motivo que desencadeou a vinda de imigrantes alemães para o Brasil. "Após a unificação da Alemanha, os lideres políticos católicos e a população que professavam essa religião, passam a sofrer perseguições, que culminaram na expulsão de inúmeras ordens religiosas e também na saída do país, dos políticos católicos que encontraram na emigração uma solução" (NEGRÃO, 2008, p. 54).

Assim que chegaram ao país, os imigrantes alemães solicitaram ao governo imperial que construísse escolas para atender seus filhos, porém, não haviam escolas suficientes para atender a população que residiam nos centros urbanos e nem as que residiam nos núcleos coloniais. A ausência de escolas para atender os filhos de imigrantes foi solucionada com a criação de escolas que atendessem as necessidades da comunidade, tanto sociais como culturais e principalmente pela religião que professavam (NEGRÃO, 2008).

Outra temática que emergiu do levantamento e da leitura das teses e dissertações foi relacionada à identidade dos grupos étnicos. As pesquisas encontradas são unânimes em afirmar que a preservação e manutenção da identidade dos grupos étnicos estiveram presentes no processo de colonização no Brasil. Além da criação de escolas para seus filhos, os imigrantes utilizaram outros mecanismos para preservação da língua materna e da cultura como a religião, as festas, as tradições, os costumes, a música, dentre outros, que elencam o rol de tentativas de manutenção da identidade étnica (BARBOSA, 2010).

Com relação a distribuição dos trabalhos notou-se que a maior concentração reside na região Sul, devido a temática tornar-se objeto de estudo em virtude da presença de diversos grupos étnicos. 
Tabela 2- Tabela da produção científica por região

\begin{tabular}{|c|c|}
\hline Região & Total de trabalhos \\
\hline Centro-oeste & 0 \\
\hline Norte & 0 \\
\hline Nordeste & 0 \\
\hline Sudeste & 15 \\
\hline Sul & 12 \\
\hline TOTAL & $\mathbf{2 5}$ \\
\hline
\end{tabular}

Fonte: Elaborada pela autora

A maioria dos trabalhos concentrou-se na área da Educação, o que vai ao encontro com a afirmação de Lombardi (2003) ao afirmar que a historiografia da educação é um campo de estudo que tem por objeto de investigação as produções históricas e por objeto de estudo o educacional. Sendo trabalhos sobre instituições que tem objetivo de transmitir conhecimentos (Instituições Escolares), nada mais coerente estarem vinculados à Educação, enquanto área.

No que tange as temáticas norteadoras das pesquisas que se centram sobre a educação e a imigração destacam-se os estudos relacionados a etnia alemã, totalizando 10 produções, seguida do grupo italiano que totaliza 5 produções e as demais que abordam as etnias holandesas, polonesa e ucraniana, japonesa e árabe.

Outro aspecto que merece atenção pelos pesquisadores e autores é a estrutura dos resumos de dissertações e teses apresentadas nas produções acadêmicas. Constatou-se que alguns textos não contemplavam as informações básicas acerca da temática pesquisada, ou seja, faltam elementos necessários e básicos para que o leitor compreenda do que trata a pesquisa. Para que um resumo informe o leitor e contemple os elementos básicos é necessário que o autor apresente as seguintes informações: uma introdução do que se trata a pesquisa, qual é o objeto investigado e a questão norteadora ou problema que se apresenta para a investigação; quais são os objetivos da pesquisa realizada e coerentemente qual a metodologia e técnicas empregadas para o desenvolvimento da investigação. Articulado aos objetivos e a metodologia o referencial teórico escolhido pelo pesquisador precisa estar claro e coerente com a concepção teórica adotada. Por fim, apresentam-se os resultados e as conclusões obtidas com a realização da pesquisa (SEVERINO, 2002). Esses são elementos básicos que devem constar em um resumo que pretende informar e esclarecer o leitor acerca do tema pesquisado.

Mediante a análise dos resumos das produções acadêmicas encontradas buscou-se analisar o conteúdo para entender o objeto de estudo, como foi estudado e os resultados encontrados a partir dos encaminhamentos metodológicos delineados. Entretanto, para procedimento da análise do texto foi necessário ampliar e proceder a leitura da dissertação ou tese na sua integra para compreensão do objeto, dos objetivos e resultados encontrados, pois algumas informações estavam ausente ou subentendidas.

Em relação ao referencial teórico utilizado pelos pesquisadores, a maioria não explicita no resumo a postura teórica assumida para o desenvolvimento da investigação. Há ainda, um certo ecletismo presente nas pesquisas relacionadas a história das instituições escolares, o que torna prejudicial para este campo, pois escamoteia a verdade dos fatos e impõe uma neutralidade científica. Mas, 


\begin{abstract}
Ao contrário, todo conhecimento produzido implica e pressupõe métodos e teorias que enformam (no sentido de dar forma) o processo e o resultado da construção do conhecimento científico, sendo estes igualmente produtos sociais e históricos. Mesmo quando os trabalhos não explicitam os métodos e as teorias utilizadas, é evidente que, apesar de esta dimensão ficar subjacente ao texto, não se deixa de adotar pressuposições ontológicas e gnosiológicas, posto que estas permeiam toda a produção de conhecimentos, todo processo e resultado do pensar do homem. (LOMBARDI, 2004, p. 146).
\end{abstract}

O presente momento da produção historiográfica sobre a história das instituições escolares caracteriza-se por uma fragmentação epistemológica e temática que dificulta a compreensão da totalidade do fenômeno educacional. Muitos desses estudiosos veem nessa crise paradigmática um largo movimento antimarxista e o abandono da perspectiva histórica. (NOSELLA; BUFFA, 2005).

\title{
Considerações finais
}

Buscou-se por meio deste estudo, problematizar a produção acadêmica referente a educação e imigração no país, a partir do levantamento do Estado do Conhecimento de teses e dissertações. Com este estudo percebeu-se que ainda é restrito o número de trabalhos sobre a educação dos imigrantes no Brasil, mas é um grande campo de pesquisa e muitas indagações podem ser feitas sobre o tema.

A partir dos trabalhos analisados, compreende-se que despontam novas perspectivas e desafios para a história das instituições escolares no Brasil. Com base no levantamento das produções acadêmicas, salienta-se a necessidade de ampliarem-se os estudos sobre a História das Instituições Escolares, contribuindo para a reconstrução histórica das instituições étnicas, para o entendimento acerca da sua singularidade e contribuição para a história regional. Este levantamento foi desenvolvido no âmbito dos estudos sobre a História de Instituições Escolares, procurando fomentar e consolidar a produção do conhecimento sobre a temática. A análise da criação das instituições escolares insere-se no debate histórico em que a investigação é reforçada "[...] em razão da determinação histórica que exerce sobre o fenômeno educativo, e do ponto de vista do enfoque, dado que pesquisar em história da educação é investigar o objeto educação sob a perspectiva histórica" (SAVIANI, 1998, p. 11-12).

A pesquisa historiográfica acerca das instituições étnicas tem privilegiado um rol de temas que suscitam a investigação acerca da arquitetura escolar, da comunidade e da região em que a escola está situada, dos projetos para construção do prédio e a sua relação com o contexto histórico, das narrativas de professores e alunos, além de outras questões que podem se tornar o ponto de partida para pesquisas e estudos acerca das escolas étnicas no país.

A historiografia mencionada demonstra a relevância do tema e a importância de analisar os aspectos relacionados a substituição do trabalho escravo pelo trabalho assalariado de origem imigrante. Nesse contexto histórico, cabe destacar a necessidade de constituição de escolas étnicas para os filhos dos imigrantes já que as escolas públicas eram precárias e não atendiam as necessidades da população brasileira. 


\section{Referências}

ANDERY, Maria Amélia et al. A prática, a história e a construção do conhecimento: Karl Marx (1818-1883). In: Para compreender a ciência: uma perspectiva histórica. $5^{\mathrm{a}}$ Ed. Rio de Janeiro: Espaço e tempo, 1994. p. 395-425.

KREUTZ, Lúcio. Escolas étnicas na história da educação brasileira: a contribuição dos imigrantes. IN: STEPHANOU, Maria; BASTOS, Maria Helena. (orgs). Histórias e memórias da educação no Brasil, vol. II: século XIX. 4. ed. Petrópolis, RJ: Vozes, 2011.

LOMBARDI, José Claudinei. História e historiografia da educação no Brasil. In: et al. Educação em debate: perspectivas, abordagens e historiografia. Campinas: Autores Associados, 2006.

. História e historiografia da educação: atentando para as fontes. In: LOMBARDI, J. C.; NASCIMENTO, M. I. M. (Orgs.). Fontes, história e historiografia da educação. Campinas: Autores Associados, 2004.

LÖWY, Michael. As aventuras de Karl Marx contra o Barão de Münchhausen. 5 ed. São Paulo: Cortez, 1994.

MARX, K.; ENGELS, F. A ideologia alemã em particular. In: A ideologia alemã. São Paulo, Martins Fontes, 1998, p. 7-54.

MATTOS, I. R. de. O Tempo Saquarema: a formação do Estado imperial. 2 ed. São Paulo: Hucitec, 1990.

NASCIMENTO, Maria Isabel Moura; SANDANO, Wilson; LOMBARDI, José Claudinei; SAVIANI, Dermeval. Instituições escolares no Brasil. Campinas: Autores Associados, 2007.

NETTO, José Paulo. Relendo a teoria marxista da História. IN: SAVIANI, Demerval. et al. História e história da educação. 3. ed. Campinas: Autores Associados, 2006.

RENK, Vaquiria Elenita. Aprendi a falar português na escola! $O$ processo de nacionalização das escolas étnicas polonesas e ucranianas no Paraná. 2009. Tese (doutorado em educação). Universidade Federal do Paraná.

ROMANOWSKI, J. P ; ENS, R. T. As pesquisas denominadas do tipo "estado da arte" em educação. Diálogo Educacional, Curitiba, v. 6, n. 19, p. 37-50, set./dez. 2006.

SANFELICE, José Luis. História das instituições escolares. IN: NASCIMENTO, Maria Isabel Moura. [et al] (orgs). Instituições escolares no Brasil: conceito e reconstrução histórica. Campinas: Autores Associados, 2007.

SAVIANI, Dermeval. O debate teórico e metodológico no campo da história e sua importância para a pesquisa educacional. IN: educação. 3. ed. Campinas: Autores Associados, 2006. 
SOARES, Magda Becker; MACIEL, Francisca Pereira. Alfabetização no Brasil: o estado do conhecimento. Disponível em: http://www.mec.inep.gov.br, 2000. Acesso em: 23 jan. 2014.

VIDAL, Diana Gonçalves; FARIA FILHO, Luciano Mendes de. História da educação no Brasil: a constituição histórica do campo (1880-1970). Rev. Bras. Hist. [online]. 2003, vol. 23, n.45, pp. 37-70. ISSN 1806-9347.

VILLELA, Heloisa de O. S. Entre o "saber fazer" e a profissionalização a escola normal do século XIX e a constituição da cultura profissional docente. In: MIGUEL, Maria Elisabeth Blanck e CORRÊA, Rosa Lydia Teixeira (orgs.). A educação escolar em perspectiva histórica. Campinas, SP: Autores Associados, 2005.

Recebido: $\quad$ setembro-15 Aprovado: outubro-15 